\title{
Representative Ground-motion Ensembles for Several Major Earthquake Scenarios in New Zealand
}

\author{
K. Tarbali \& B.A. Bradley \\ Department of Civil and Natural Resources Engineering, University of \\ Canterbury, Christchurch.
}

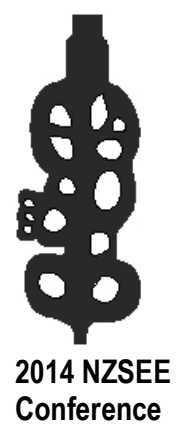

\begin{abstract}
This paper develops representative ground motion ensembles for several major earthquake scenarios in New Zealand. Cases considered include representative ground motions for the occurrence of Alpine, Hope, and Porters Pass earthquakes in Christchurch, and the occurrence of Wellington, Wairarapa, and Ohariu, fault ruptures in Wellington. Challenges in the development of ground motion ensembles for subduction zone earthquakes are also highlighted. The ground motions are selected based on the generalized conditional intensity measure (GCIM) approach, ensuring that the ground motion ensembles represent both the mean, and distribution of ground motion intensity which such scenarios could impose. These scenario-based ground motion sets can be used to complement ground motions which are often selected in conjunction with probabilistic seismic hazard analysis, in order to understand the performance of structures for the question "what if this fault ruptures?"
\end{abstract}

\section{INTRODUCTION}

Conducting nonlinear response history analysis of structures for the purpose of seismic performance assessment requires selecting appropriate ground-motion time series, which provide an appropriate representation of the seismic hazard at the site. Although, it is common to conduct seismic performance assessment based on the results from probabilistic seismic hazard analysis (PSHA), scenario-based assessment can be highly informative and provide complementary insights (Bommer 2002).

Many methods have been proposed to select ground motions based on matching the acceleration response spectrum of the selected motions to a target spectrum and considering implicit causal earthquake parameters (e.g. magnitude, source-to-site distance, site conditions) (Bradley 2010a, Katsanos et al. 2010). Such approaches generally have several shortcomings, namely: (1) ground motion severity is a function of the amplitude, frequency content, and duration of the motion, which is not embodied simply in response spectral ordinates; (2) ground motion ensembles should represent the full distribution of possible motions and not just the mean; and (3) the ground motion ensemble should be representative of all the seismic sources which contribute to the hazard at the site. These shortcomings have been addressed through the generalized conditional intensity measure (GCIM) approach developed by Bradley (2010a, 2012). In addition, the GCIM-based ground motion selection method has been extended to select ground motions based on the results from scenario seismic hazard analysis (Tarbali and Bradley 2014).

In the present study, the GCIM method is utilized to select representative ground motion ensembles for several major earthquake scenarios in New Zealand. The earthquake rupture forecast model developed by Stirling et al. (2012) is used to obtain the characteristics of seismic sources and the New Zealand-specific ground motion prediction equation (GMPE) developed by Bradley (2013) is used to predict the spectral acceleration intensity, peak ground acceleration, and peak ground velocity of motion in seismic hazard analysis and ground-motion selection stages. Other intensity measures of motion are calculated by using GMPEs developed to predict the intensity of motion from shallow crustal events, presented in the next section. 


\section{GROUND-MOTION SELECTION FOR SCENARIO RUPTURES IN CHRISTCHURCH}

\subsection{Dominant seismic sources}

In order to identify the scenario ruptures with significant contributions to the seismic hazard at a generic location in central Christchurch (Latitude $-43: 5300^{\circ}$; Longitude $172.6203^{\circ}$ ), probabilistic seismic hazard analyses are conducted using the open-source seismic-hazard-analysis software OpenSHA (Field et al. 2003). The soil condition at the site is assumed to be site class D according to NZS1 170.5 (2004), with an inferred time-averaged $30 \mathrm{~m}$ shear wave velocity of $V_{s 30}=250 \mathrm{~m} / \mathrm{s}$. Figure 1 presents the deaggregation of the seismic hazard at this site for both peak ground acceleration (PGA) and $2 \mathrm{~s}$ period spectral acceleration $(\mathrm{SA}(2.0 \mathrm{~s}))$ for a $10 \%$ probability of exceedance in 50 years. As seen in this figure, seismic hazard at this generic site in Christchurch is mostly dominated by events with small magnitudes and small source-to-site distances (mostly from distributed seismicity) for PGA and SA ordinates at lower vibration periods. However, as shown for the SA(2.0s) hazard, major events with large magnitudes and moderate-to-large source-to-site distances dominate at long vibration periods (specifically $\mathrm{T}>1 \mathrm{~s}$ ).

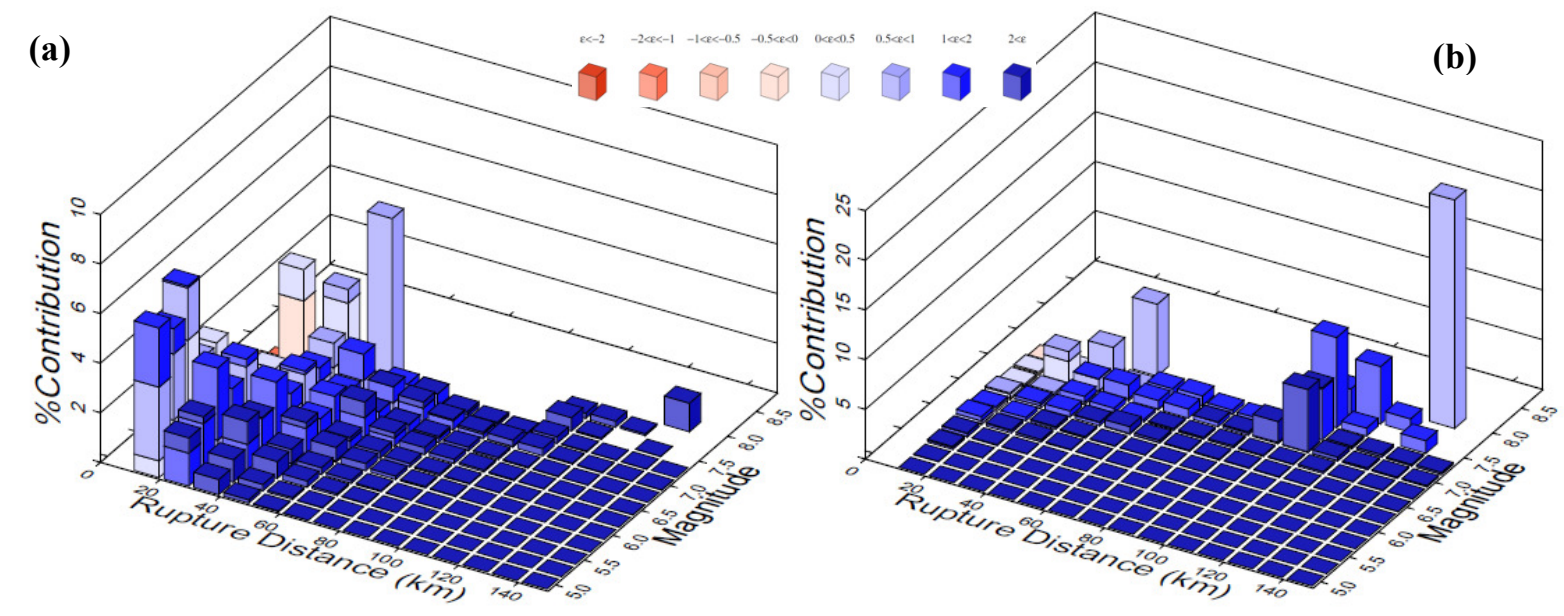

Figure 1. Deaggregation of seismic hazard in Christchurch for: (a) PGA; and (b) SA (2.0s) for a 10\% probability of exceedance in 50 years

Based on the scenarios with a large contribution to the seismic hazard for different periods of vibration, ground shaking produced in Christchurch due to ruptures of the Alpine, Hope, and Porters Pass faults is considered in this study for scenario ground-motion selection. Characteristics of these scenario ruptures are presented in Table 1.

Table 1. Characteristics of the considered scenario ruptures for Christchurch

\begin{tabular}{cccc}
\hline Fault & Magnitude, $M_{w}$ & Rupture distance, $R_{\text {rup }}(\mathrm{km})$ & Rupture mechanism \\
\hline Alpine (Fiord-Kelly segment) & 8.1 & 133 & Strike-slip \\
Hope (Conway segment) & 7.45 & 106 & Strike-slip \\
Porters Pass & 7.45 & 44 & Strike-slip \\
\hline
\end{tabular}

\subsection{Intensity measures of the considered scenario ruptures}

Table 2 presents median predicted values of several intensity measures for the rupture scenarios considered for Christchurch. As shown, the spectral acceleration ordinates (and PGA) of the scenario with a smaller source-to-site distance (i.e. Porters Pass) are greater than those for scenarios with larger source-to-site distances (i.e. Alpine and Hope), especially for periods of vibration smaller than $\mathrm{T}=2 \mathrm{~s}$. Also, the scenario spectrum for all of these scenario ruptures have smaller values compared with the elastic site spectra for Christchurch (NZS1170.5 2004) (as illustrated subsequently). Similarly, a Porter Pass rupture is predicted to produce a greater PGV compared to Alpine and Hope faults ruptures. 
As presented in Table 2, the Alpine fault rupture has a median predicted significant duration of $56.2 \mathrm{~s}$ for the considered generic site at Christchurch, which is double the significant duration from the Porter Pass rupture (due to a smaller magnitude and source-to-site distance).

Table 2. Median intensity measures of the considered rupture scenarios for Christchurch

\begin{tabular}{cccccccc}
\hline Fault & $\begin{array}{c}\text { PGA } \\
(\mathrm{g})\end{array}$ & $\begin{array}{c}\mathrm{SA}(0.5 \mathrm{~s}) \\
(\mathrm{g})\end{array}$ & $\begin{array}{c}\mathrm{SA}(1.0 \mathrm{~s}) \\
(\mathrm{g})\end{array}$ & $\begin{array}{c}\mathrm{SA}(2.0 \mathrm{~s}) \\
(\mathrm{g})\end{array}$ & $\begin{array}{c}\text { PGV } \\
(\mathrm{cm} / \mathrm{s})\end{array}$ & $\begin{array}{c}\text { CAV } \\
(\mathrm{g} . \mathrm{s})\end{array}$ & $\begin{array}{c}\text { Ds595 } \\
(\mathrm{s})\end{array}$ \\
\hline $\begin{array}{c}\text { Alpine (Fiord-Kelly } \\
\text { segment) }\end{array}$ & 0.07 & 0.13 & 0.11 & 0.07 & 12.1 & 0.9 & 56.2 \\
$\begin{array}{c}\text { Hope (Conway segment) } \\
\text { Porters Pass }\end{array}$ & 0.05 & 0.10 & 0.07 & 0.04 & 7.9 & 0.5 & 36.6 \\
\hline
\end{tabular}

\subsection{Selected ground motions for scenario earthquakes in Christchurch}

Prior to selecting ground motions, it is important to identify the type of engineering system considered for seismic performance assessment, so that the selection process can aim to place emphasis on those intensity measures that are important to determine the characteristic response of the system. For instance, peak inter-story drift of a building structure is mostly affected by spectral acceleration ordinates of the applied motion for periods near the first several vibration modes of the structure. In contrast, the response of geotechnical structures with liquefaction-susceptible soils can be significantly affected by significant duration and cumulative effects of a ground motion. This issue has been addressed in the GCIM-based ground-motion selection method by using a weight vector in the selection algorithm (Bradley 2012), to weight these different ground motion aspects in record selection. In order to consider different aspects of a ground motion, including the intensity, frequency content, and duration, the selection process is based on appropriateness of multiple intensity measures for the considered rupture scenarios. The considered intensity measures in this study are: spectral acceleration for 18 vibration periods $(0.05,0.075,0.1,0.15,0.2,0.25,0.3,0.4,0.5,0.75,1.0,1.5,2.0$, 3.0, 4.0, 5.0, 7.5, and 10.0 s); cumulative absolute velocity (CAV) (Campbell and Bozorgnia 2010), and significant durations $\left(\mathrm{D}_{\mathrm{s} 595}\right.$ and $\left.\mathrm{D}_{\mathrm{s} 575}\right)$ (Bommer et al. 2009). The relative importance of these intensity measures is applied by using a weight vector presented in Table 3, in which the emphasis is placed on SA ordinates, significant duration, and CAV. Additional intensity measures such as peak ground acceleration (PGA); peak ground velocity (PGV); acceleration spectrum intensity (ASI) (Bradley 2010b); spectrum intensity (SI) (Bradley et al. 2009); and displacement spectrum intensity (DSI) (Bradley 2011) were also considered, but it was found that zero weight vector values for these intensity measures still yielded appropriate selected ground motions.

Table 3. Weight vector considered for ground-motion selection for Christchurch

\begin{tabular}{cccc}
\hline SA & CAV & Ds575 & Ds595 \\
\hline $0.7^{1}$ & 0.1 & 0.1 & 0.1 \\
\hline${ }^{1}$ Evenly distributed to 18 SA ordinates between $\mathrm{T}=0-10 \mathrm{~s}$ &
\end{tabular}

A total of 20 ground-motion time series are selected for each of the considered scenarios, from the NGA database of strong ground motions from shallow crustal earthquakes (Chiou et al. 2008). For each scenario considered, the NGA database was limited to those motions one order of magnitude greater and smaller than the corresponding rupture scenario magnitude. The motions in the NGA database have been processed to be directly used in seismic response analysis and are accessible at http://peer.berkeley.edu/nga/. The ground motions selected in this study can be downloaded from https://sites.google.com/site/brendonabradley/research/ground-motion-selection.

Figure 2 presents the median, $16^{\text {th }}$ and $84^{\text {th }}$ percentiles, and the individual spectral acceleration ordinates of the selected motions (which have been amplitude scaled) along with the predicted target spectrum and the target $16^{\text {th }}$ and $84^{\text {th }}$ percentile spectra for the considered rupture scenarios. In addition, Figure $2 d$ presents cumulative distribution of significant duration (i.e. $D_{\mathrm{s} 595}$ ) for the 
considered rupture scenarios and the corresponding target distribution. Based on the presented results, it can be seen that the distribution of the selected motions appropriately represents the distribution of the considered intensity measures predicted by the corresponding GMPEs.
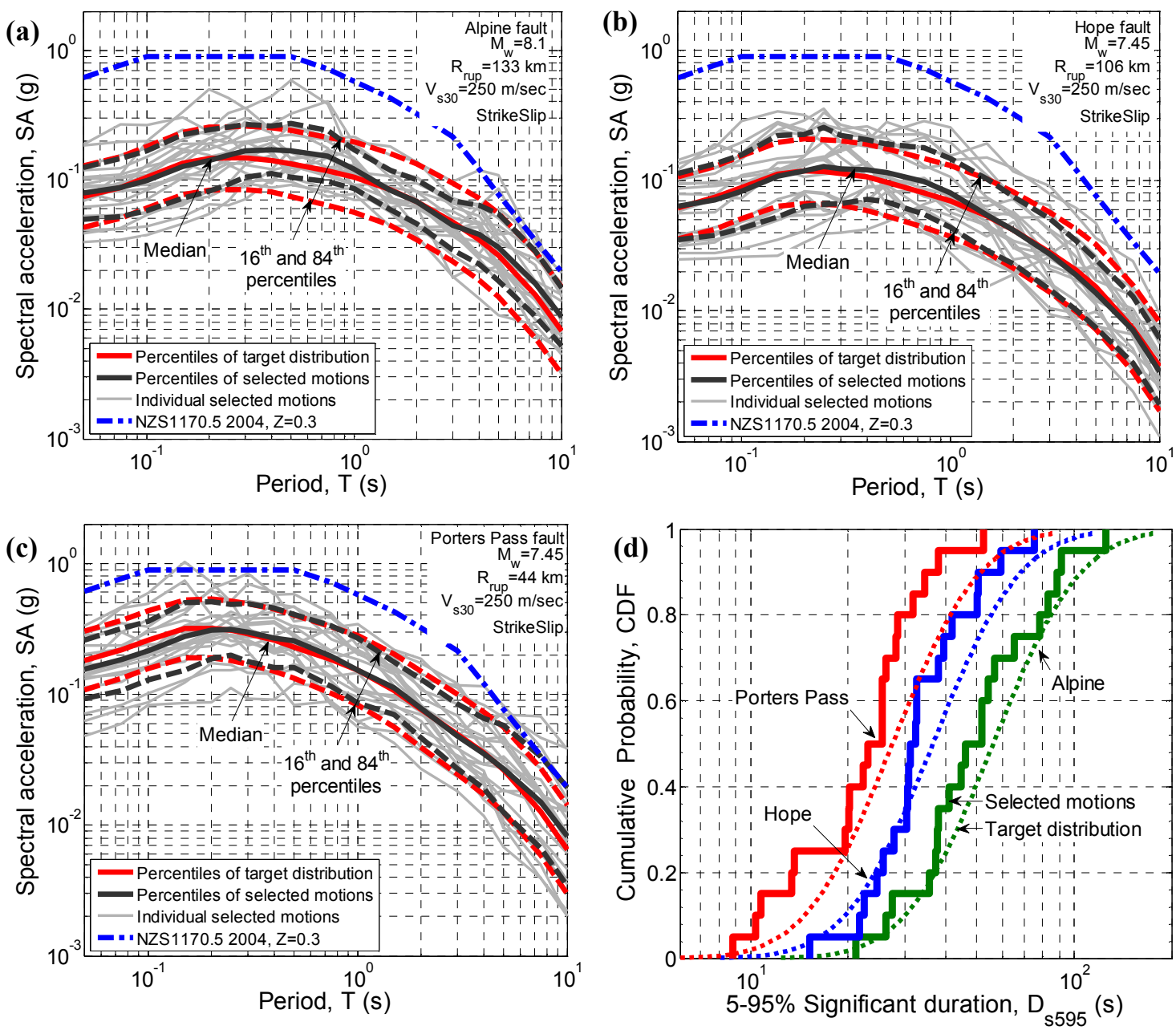

Figure 2. SA ordinates of the selected motions and the corresponding median, $16^{\text {th }}$, and $84^{\text {th }}$ percentile spectra representing: (a) Alpine; (b) Hope; (c) Porters Pass scenario ruptures; and (d) cumulative distribution of significant duration and the corresponding target distribution for the considered rupture scenarios

\subsection{Comparison of properties of selected ground motions}

As seen in Figure 2, the predicted median scenario spectrum, the median spectrum of the selected motions, and the individual acceleration response spectrum of majority of the selected motions for the corresponding scenario ruptures are below the elastic site spectra presented in NZS1170.5 (2004) for Christchurch. In addition, as presented in Figure $2 \mathrm{~d}$, the $M_{w} 8.1$ rupture of the Alpine fault and $M_{w} 7.45$ rupture of the Hope fault (both with great source-to-site distances) will produce motions with long significant durations, whereas $M_{w} 7.45$ rupture of the Porter Pass fault (with a smaller source-tosite distance) will result in motions with shorter significant durations. The large differences in significant duration of the considered rupture scenarios and the considerable effect of duration on seismic response of engineering systems illustrates the importance of considering this intensity measure when selecting ground motions for seismic response analysis.

Considering the fact that the implicit causal parameters of ground motion, such as magnitude and source-to-site distance, are not explicitly considered in the GCIM-based ground-motion selection methodology, it is worthwhile examining the distribution of these parameters for the selected motions 
with respect to each scenario rupture. As illustrated in Figure 3, the selected motions for Hope and Porters Pass faults rupture are well distributed with respect to the causal rupture scenario (i.e. the $16^{\text {th }}$ to $84^{\text {th }}$ percentile range of $M_{w}$ and $R_{\text {rup }}$ encompass the scenario itself). In contrast, the selected motions for Alpine fault rupture have a lower magnitude distribution than the scenario itself. Clearly, this is caused by the paucity of recorded ground motions with $M_{w}>7.5 \sim 8$, in contrast to a relative abundance in the recorded motions during events with smaller magnitudes.
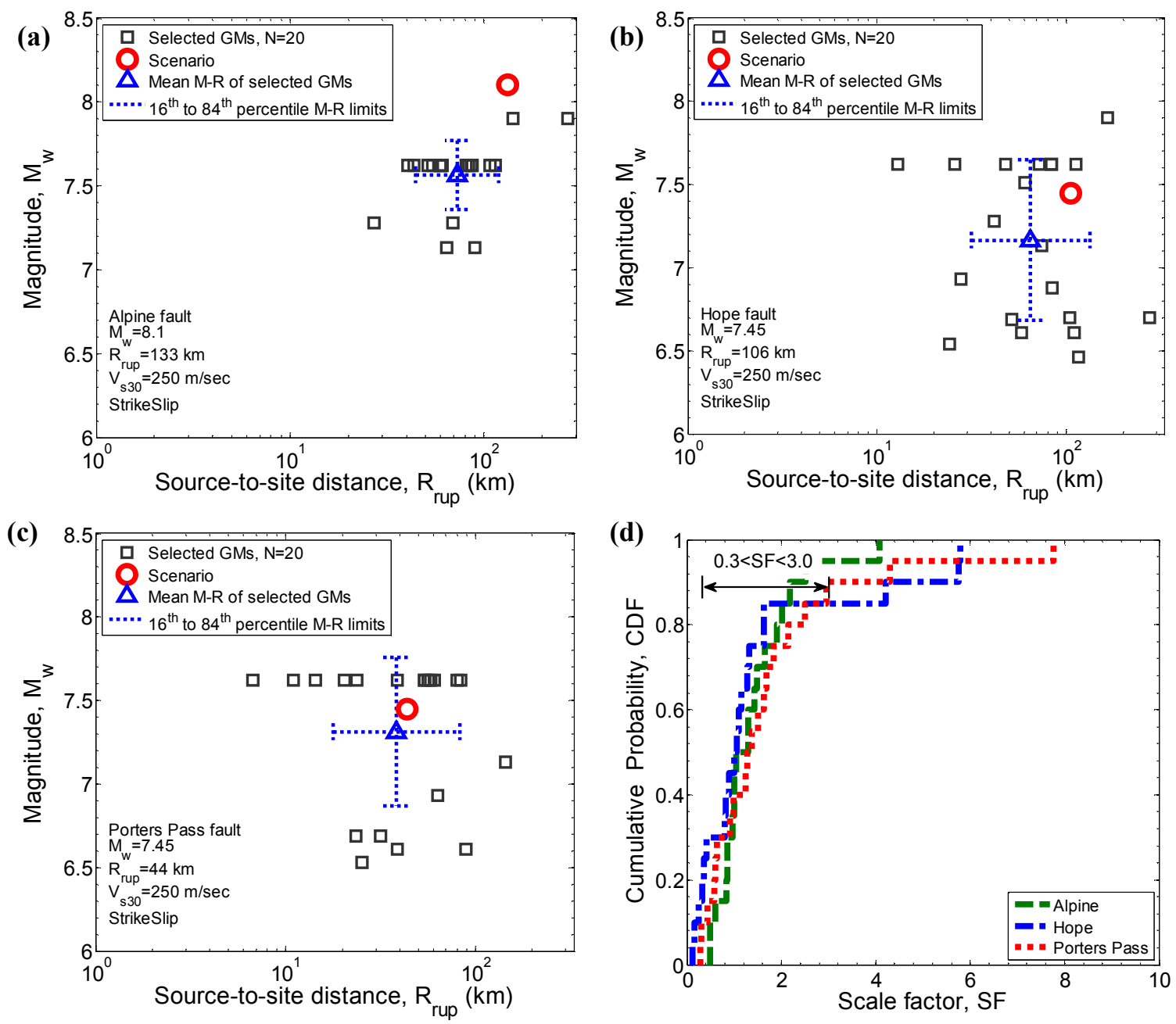

Figure 3. Magnitude-distance distribution of the selected motions representing: (a) Alpine; (b) Hope; (c) Porters Pass scenario ruptures, and (d) cumulative distribution of the amplitude scale factor of the selected motions

In addition to the distributions of the causal parameters $\left(M_{w}, R_{\text {rup }}\right)$, the applied amplitude scale factor, $S F$, required for the selected motions can be used to check the quality of the obtained suite of ground motions. Figure 3 illustrates that more than $80 \%$ of the amplitude scale factors for the rupture of the Hope fault and $65 \%$ of the amplitude scale factors for the rupture of the Alpine and Porter Pass faults are favourably in the range of 0.3 to 3.0 , which is often recommended as scaling limits in seismic design standards.

It is important to note that there is a trade-off when selecting motions with an appropriate representation for the predicted intensity measures (SA, $D_{S 595}$ etc.); magnitude-distance distribution (or other implicit causal parameters); and amplitude scale factors. While ideally the selected motions would have the appropriate representation of implicit causal parameters and amplitude scale factors near 1.0, an emphasis in ground motion selection should be placed on the appropriateness of the explicit intensity measures of the ground motion (SA, $D_{S 595}$ etc.) rather than the implicit causal 
parameters, as elaborated upon by Bradley (2012) and mentioned in the revision to ASCE/SEI7-10 (2010).

\section{GROUND-MOTION SELECTION FOR SCENARIO RUPTURES IN WELLINGTON}

\subsection{Dominant seismic sources}

PSHA has been conducted for a generic location in central Wellington (Latitude $-41: 2889^{\circ}$ and Longitude $174.7772^{\circ}$ ) for a site class $\mathrm{D}$ soil (NZS1170.5 2004) with $\mathrm{V}_{\mathrm{s} 30}=250 \mathrm{~m} / \mathrm{s}$. Figure 4 illustrates the seismic hazard deaggregation for PGA and SA(2.0s) for a $10 \%$ probability of exceedance in 50 years. Based on the obtained results for deaggregation of the seismic hazard, it is observed that the seismic hazard at this generic location in wellington is mostly dominated by events with large magnitudes and very small source-to-site distances. By identifying the scenarios with large contributions to the seismic hazard in Wellington, ruptures of the Wellington, Wairarapa, and Ohariu faults are considered in this study for scenario ground-motion selection. Characteristics of these scenario ruptures are presented in Table 4. It is important to note that the presented deaggregation results illustrates the contribution of a $M_{w} 8.64$ rupture of the Hikurangi subduction-zone (Wellington Max segment) within $18 \mathrm{~km}$ distance from Wellington. Since the focus of this study is to select ground motions to represent shallow-crustal ruptures, this scenario has not been considered for ground-motion selection for Wellington in this paper. The issues related to selecting ground motions to represent subduction-zone earthquakes are discussed later in this paper.
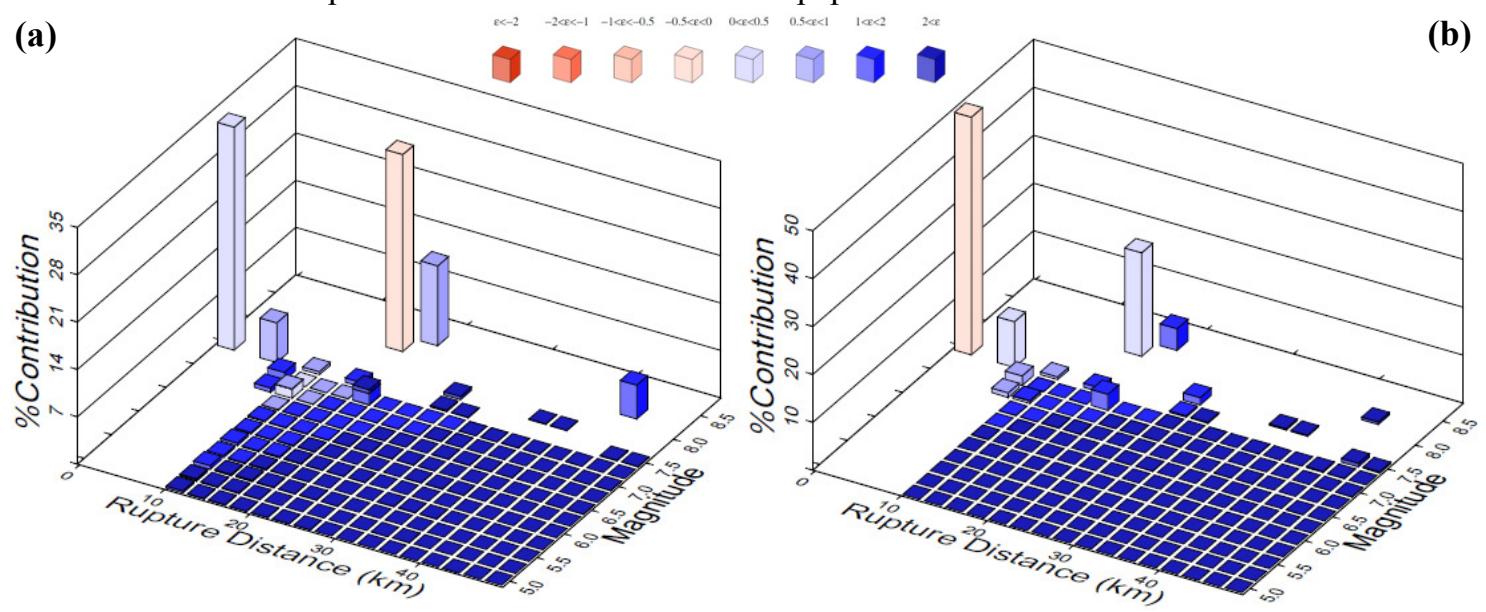

Figure 4. Deaggregation of seismic hazard in Wellington for: (a) PGA; and (b) SA at 2 s vibration period for a $10 \%$ probability of exceedance in 50 years

Table 4. Characteristics of the considered scenario ruptures for Wellington

\begin{tabular}{cccc}
\hline Fault & Magnitude, $M_{w}$ & Rupture distance, $R_{r u p}(\mathrm{~km})$ & Rupture mechanism \\
\hline Wellington & 7.53 & 1.0 & Strike-slip \\
(Well-Hutt Valley segment) & 8.17 & 17.0 & Strike-slip \\
Wairarapa (Nicholson segment) & 7.36 & 6.0 & Strike-slip \\
Ohariu (South segment) &
\end{tabular}

\subsection{Intensity measures of the considered scenario ruptures}

Table 5 presents the median intensity measures for the rupture scenarios considered for Wellington. As presented, the Wellington fault with a large magnitude and very small source-to-site distance, and the Wairarapa fault with a very large magnitude and small source-to-site distance have close median SA ordinates. In addition, because of the large magnitude of the Wairarapa scenario rupture (i.e. $\left.M_{w} 8.17\right)$, the median predicted significant duration of the corresponding scenario ground motion is 
considerably greater than that for the other ruptures. In addition, the Wellington rupture results in greater PGV compared to the Wairarapa and Ohariu ruptures, because of the very small source-to-site distance from this fault to the site.

Table 5. Median intensity measures of the considered rupture scenarios for Wellington

\begin{tabular}{cccccccc}
\hline Fault & $\begin{array}{c}\text { PGA } \\
(\mathrm{g})\end{array}$ & $\begin{array}{c}\mathrm{SA}(0.5 \mathrm{~s}) \\
(\mathrm{g})\end{array}$ & $\begin{array}{c}\mathrm{SA}(1.0 \mathrm{~s}) \\
(\mathrm{g})\end{array}$ & $\begin{array}{c}\mathrm{SA}(2.0 \mathrm{~s}) \\
(\mathrm{g})\end{array}$ & $\begin{array}{c}\text { PGV } \\
(\mathrm{cm} / \mathrm{s})\end{array}$ & $\begin{array}{c}\text { CAV } \\
(\mathrm{g} . \mathrm{s})\end{array}$ & $\begin{array}{c}\text { Ds595 } \\
(\mathrm{s})\end{array}$ \\
\hline $\begin{array}{c}\text { Wellington } \\
\text { (Well-Hutt Valley segment) }\end{array}$ & 0.6 & 1.0 & 0.9 & 0.6 & 104.7 & 2.0 & 24.0 \\
$\begin{array}{c}\text { Wairarap } \\
\text { (Nicholsonsegment) }\end{array}$ & 0.7 & 1.1 & 0.8 & 0.4 & 74.7 & 2.0 & 41.5 \\
Ohariu (South segment) & 0.5 & 0.7 & 0.6 & 0.4 & 70.0 & 2.1 & 21.0 \\
\hline
\end{tabular}

\subsection{Selected ground motions for scenario earthquakes in Wellington and comparison of their properties}

Similar to the Christchurch scenarios previously discussed, sets of 20 ground motions were selected for each of the three considered ruptures for Wellington using the GCIM-based ground motion selection method. Figure 5 illustrates the conformity of the SA ordinates of the selected motions to the predicted spectral acceleration of the three scenario ruptures in Wellington. As shown in Figure 5a, the predicted median scenario spectrum, and the median spectrum of the selected motions, for rupture of the Wellington fault (which has the highest contribution to the seismic hazard at the considered generic site in central Wellington) are very close to the elastic code spectra (NZS1170.5 2004) at medium to long periods of vibration. It should be noted that the near-fault effect has been considered in calculating the code elastic site spectra for Wellington (NZS1170.5 2004) .

Figure 6 provides a comparison of the magnitude-distance distribution of the selected motions with respect to magnitude-distance pair of the corresponding scenarios. In the case of the Wellington and Ohariu ruptures, it can be seen that the magnitude distribution of the selected motions corresponds well to the expected rupture magnitude, while the magnitudes of the selected motions for the Wairarapa rupture fall below that expected for that event. In terms of source-to-site distances it can be seen that the ground motions selected for the Wellington and Ohariu ruptures are notably larger than those of representative of these scenarios, while for the Wairarapa rupture the source-to-site distance distribution of the selected motions is closer to that scenario (although still slightly larger). Clearly, these biases are related to the paucity of the motions recorded from large magnitude events with short source-to-site distances. As already noted earlier however, it is important to remember that groundmotion selection requires a trade-off between the intensity measure values of the ground motions themselves, and implicit causal parameters such as $M_{w}, R_{\text {rup }}$ etc. Because it is known that there is little variation of ground motion properties in the immediate near-field (i.e. $R_{\text {rup }}=0-10 \mathrm{~km}$ ) then the distance biases shown in Figure 6 are not considered significant. When considering the resulting ground motions selected for the Wairarapa rupture scenario (Figure $5 \mathrm{~b}$ and Figure 5d), it is important to note that when comparing the selected motions with the 'target' we are implicitly assuming that the target is correct. While this is generally a reasonable assumption, in the case of rupture scenarios with very large magnitudes, $\left(M_{w} 8.17\right.$ for Wairarapa), the GMPE utilized to calculate the target distribution can be weakly constrained for such large events. Therefore, the 'target' may itself be inherently biased. Thus, the biased distribution of significant duration for the Wairarapa rupture (see Figure 5d) is considered partially the result of the inadequacy of the implemented GMPEs to calculate the corresponding target distributions for such large events.

As seen in Figure 6d, the amplitude scale factor of the selected motions are mostly large values with almost $40 \%$ of them in the 0.3-3.0 range. By comparing these results to those presented in Figure 3 for Christchurch, it is implicated that selecting ground motions for scenarios like the ones considered for Wellington (with short source-to-site distances and large magnitudes) requires scaling the existing motions using larger scale factors, as there is a shortage of motions recorded during such events in the existing strong ground motion database (Chiou et al. 2008). 

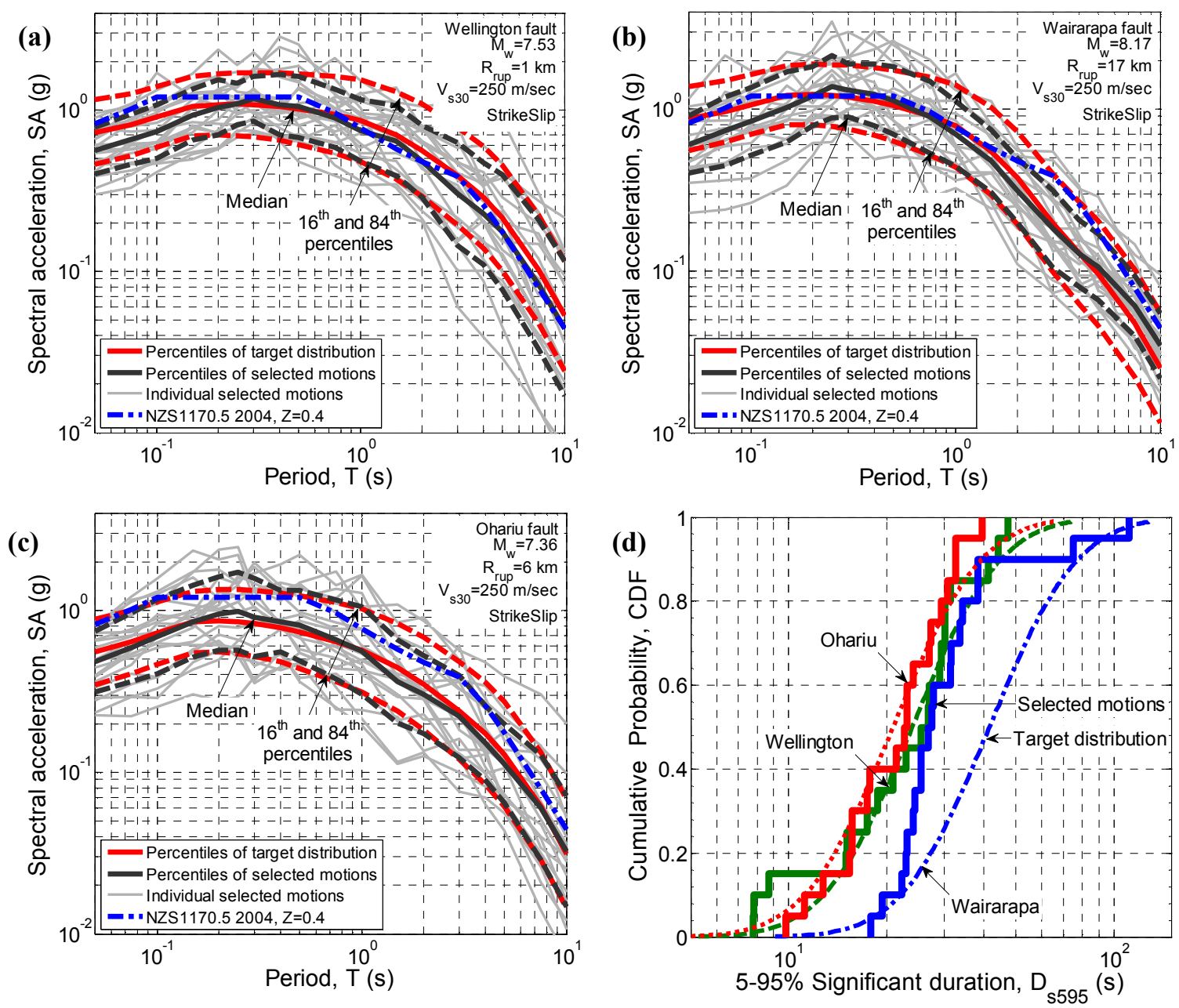

Figure 5. SA ordinates of the selected motions and the corresponding median, $16^{\text {th }}$, and $84^{\text {th }}$ percentile spectra representing: (a) Wellington; (b) Wairarapa; (c) Ohariu scenario ruptures; and (d) cumulative distribution of significant duration and the corresponding target distribution for the considered rupture scenarios

\section{SELECTING REPRESENTATIVE GROUND MOTIONS FOR SUBDUCTION-ZONE EVENTS}

The ground motions selected in this study are aimed to represent major active shallow crustal rupture scenarios in Christchurch and Wellington. However, the occurrence of major subduction-zone earthquakes (both interface and slab) should also be considered in ground-motion selection for regions prone to this type of earthquakes, such as Wellington. As noted before, in the presented deaggregation results for Wellington, the occurrence of a $M_{w} 8.64$ rupture of the Hikurangi subduction interface (Wellington Max segment) within $18 \mathrm{~km}$ distance of Wellington contributes significantly to the seismic hazard. At present, routine ground motion selection for subduction-zone events is hindered by a lack of: (1) a comprehensive database of strong ground motions recorded from subduction-zone events; and (2) appropriate subduction-zone GMPEs and correlation equations for various groundmotions intensity measures. Such efforts are topics of on-going research among the authors as well as many others in the research community. 

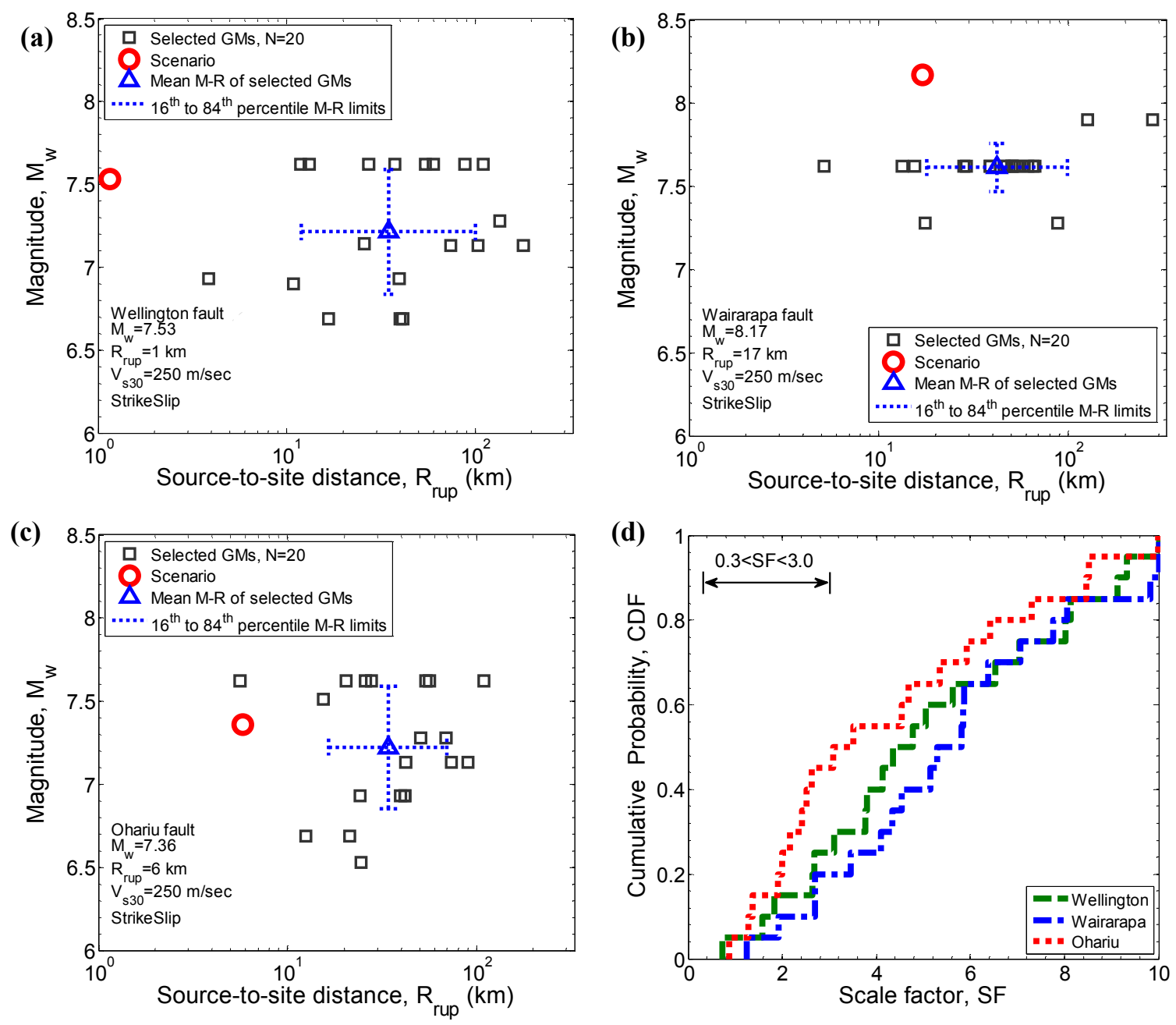

Figure 6. Magnitude-distance distribution of the selected motions representing: (a) Wellington; (b) Wairarapa; (c) Ohariu scenario ruptures, and (d) cumulative distribution of the amplitude scale factor of the selected motions

\section{CONCLUSION}

This paper demonstrates selecting ground motions to represent several major earthquake scenarios in New Zealand, using the generalized conditional intensity measure (GCIM) approach. Six different rupture scenarios were considered that pose a significant seismic hazard in Christchurch (Alpine, Hope and Porters Pass ruptures) and Wellington (Wellington, Ohariu, and Wairarapa ruptures). For each rupture scenario considered, sets of 20 ground motions were selected to appropriately represent the predicted distribution of various intensity measures (spectral accelerations, significant duration etc.). Subsets of these 20 ground motions (e.g. a subset of 7 motions) can also be utilized for standard codebased analyses. A paucity of recorded motions from events with large magnitudes and short source-tosite distances in existing strong ground motion databases impedes selecting motions for large magnitude small source-to-site distance rupture scenarios and also consequently requires the use of large amplitude scale factors to scale available motions. However, implicit causal parameters, such as magnitude and source-to-site distance, are of secondary importance when compared to explicit measures of intensity of ground motion (spectral accelerations, significant duration etc.).

\section{ACKNOWLEDGEMENT}

Financial support of the University of Canterbury and New Zealand Earthquake Commission (EQC) 
are greatly appreciated.

\section{REFERENCES}

ASCE/SEI7-10 (2010). Minimum Design Loads for Buildings and Other Structures, ASCE/SEI 7-10. American Society of Civil Engineers, Reston, Virginia.

Bommer, J. J. 2002. Deterministic vs. probabilistic seismic hazard assessment: an exaggerated and obstructive dichotomy. Journal of Earthquake Engineering 6(spec01): 43-73.

Bommer, J. J., P. J. Stafford \& J. E. Alarcón 2009. Empirical equations for the prediction of the significant, bracketed, and uniform duration of earthquake ground motion. Bulletin of the Seismological Society of America 99(6): 3217-3233.

Bradley, B. A. 2010a. A generalized conditional intensity measure approach and holistic groundmotion selection. Earthquake Engineering \& Structural Dynamics 39(12): 1321-1342.

Bradley, B. A. 2010b. Site-specific and spatially distributed ground-motion prediction of acceleration spectrum intensity. Bulletin of the Seismological Society of America 100(2): 792-801.

Bradley, B. A. 2011. Empirical equations for the prediction of displacement spectrum intensity and its correlation with other intensity measures. Soil Dynamics and Earthquake Engineering 31(8): 11821191.

Bradley, B. A. 2012. A ground motion selection algorithm based on the generalized conditional intensity measure approach. Soil Dynamics and Earthquake Engineering 40: 48-61.

Bradley, B. A. 2013. A New Zealand-Specific Pseudospectral Acceleration Ground-Motion Prediction Equation for Active Shallow Crustal Earthquakes Based on Foreign Models. Bulletin of the Seismological Society of America 103(3): 1801-1822.

Bradley, B. A., M. Cubrinovski, G. A. MacRae \& R. P. Dhakal 2009. Ground-Motion Prediction Equation for SI Based on Spectral Acceleration Equations. Bulletin of the Seismological Society of America 99(1): 277-285.

Campbell, K. W. \& Y. Bozorgnia 2010. A ground motion prediction equation for the horizontal component of cumulative absolute velocity (CAV) based on the PEER-NGA strong motion database. Earthquake Spectra 26(3): 635-650.

Chiou, B., R. Darragh, N. Gregor \& W. Silva 2008. NGA project strong-motion database. Earthquake Spectra 24(1): 23-44.

Field, E. H., T. H. Jordan \& C. A. Cornell 2003. OpenSHA: A developing community-modeling environment for seismic hazard analysis. Seismological Research Letters 74(4): 406-419.

Katsanos, E. I., A. G. Sextos \& G. D. Manolis 2010. Selection of earthquake ground motion records: A state-of-the-art review from a structural engineering perspective. Soil Dynamics and Earthquake Engineering 30(4): 157-169.

NZS1170.5 (2004). Structural design actions. Part 5: Earthquake actions - New Zealand. Wellington, NZ, Standards New Zealand.

Stirling, M., G. McVerry, M. Gerstenberger, N. Litchfield, R. Van Dissen, K. Berryman, . . . R. Langridge 2012. National seismic hazard model for New Zealand: 2010 update. Bulletin of the Seismological Society of America 102(4): 1514-1542.

Tarbali, K. \& B. A. Bradley 2014. Scenario-based ground-motion selection using the generalized conditional intensity measure (GCIM) approach. Proceedings of the 10th National Conference in Earthquake Engineering, Anchorage, AK, Earthquake Engineering Research Institute. 